\title{
The preparation of the National Environmental Action Plan (NEAP): Was it a false start?
}

\author{
Jean-Roger Mercier ${ }^{1}$
}

\begin{abstract}
In the late 80 's, the World Bank got interested in environmental matters, to the point that a tsunami of a new process (National Environmental Action Plans -NEAPS) swept across the African continent. At that time, Madagascar was still under the rule of Didier Ratsiraka, an iron rule which had started in 1975. A place where biodiversity assets are unique and fascinating, one of the best and hottest hotspots of conservation around the world; but also a place where environmental mismanagement has created severe erosion and water quality problems. What to do when the daily life of the average Malagasy is spent surviving for the very sector sustaining the country's battling economy? Some of the solutions proposed at the time materialized during the 15 years period since the 1990 adoption by the Malagasy government of the NEAP's findings and recommendations. Some of the original intentions, however, never were transformed into significant large-scale progress in environmental management. In 2006, Madagascar is still plagued with very serious poverty and environmental degradation problems. Can the lessons learned from the original design and the 15 years of application of the NEAP be useful to help the Malagasy nation move towards more sustainable and equitable development? If the answer is yes, what should the ways and means be?
\end{abstract}

\section{ONCE UPON A TIME}

I was privileged to participate in the preparation of the NEAP for Madagascar in the mid-80's.

After many efforts to help Sub-Saharan Africa (and notably the Malagasy government) develop the local infrastructure, especially in the transport, water and energy sectors, the World Bank got interested in environmental matters through an assistance to the preparation of National Environmental Action Plans. When the process was launched, very few experts had set out for such an ambiguous plan and even the basic methodology was to be invented. Partial approaches to environmental planning had been tried and tested (in particular National Conservation Strategies), but as far as the overall NEAP approach was concerned, it is fair to say that the design was done in parallel with the preparation of the first NEAPS. Madagascar and Rwanda were, for reasons that have to do with some strong personalities, the early dominance of international groups like the WorldWide Fund for nature (WWF), the World Conservation Union (IUCN) and Conservation International and also to the unique and fascinat- ing biodiversity assets of the two countries. These countries indeed came first on the radar screen of the World Bank, and the preparation of these two NEAPs garnered strong support from the international community.

\section{ROLLING UP THE SLEEVES}

The donor-funded team had strong initial views on what needed to be done to reverse the catastrophic environmental degradation of the times. François Falloux, a land tenure and agricultural specialist at the World Bank, called me up when he built his team to help with the Madagascar NEAP. I was fortunate to bring experience with Environmental Impact Assessment to the table, plus a few short and longer stays in Madagascar. I thus joined a team of several experts in biodiversity, forestry and other "green" topics. Our enthusiasm was probably in direct proportion of our political ignorance of the depth of internal struggles within the Malagasy society and our equally naive perception of the ease to transform additional financial support, which seemed to be ready to flow towards Madagascar, into improved environmental protection.

The basic objective of the Madagascar NEAP was to "curb the environmental degradation spiral by reconciling population with their environment". The NEAP was designed as a 15-year plan, which was to be in majority funded from external sources, and more marginally by the Malagasy Government. The mission was huge and we were collectively doomed, as a FOFIFA ${ }^{2}$ researcher colleague put so well, to having to help our Malagasy counterparts "choose between the ox and the lemur". While the original team was essentially composed of international experts, we rapidly co-opted several Malagasy experts and anchored our contacts with the Malagasy Government which was involved at the highest level, the then-Prime Minister Victor Ramahatra bringing an incredibly pertinent vision to this NEAP preparation. Cooperation with the international NGOs was a given, with WWF having a particularly strong and competent involvement from the onset.

Our first order of business was to define the NEAP's scope. We cast the net very widely and did not limit ourselves to conservation, though conservation was both the reason why Madagascar was so famous and courted internationally and the biggest motivation behind the preparation of the NEAP. However, we built seven components into the preparation of the NEAP, which were to correspond to programs to be implemented over a period of 15 years: 
Protecting and managing the national heritage of biodiversity, with a special emphasis on parks, reserves and gazetted natural forests, in conjunction with the sustainable development of their surrounding areas; Improving the living conditions of the population. This would be done in rural areas by improving the protection and management of natural resources. Particular attention would be paid to watershed protection, reforestation, and agro forestry. In urban areas, this would involve improving water supply and sanitation, waste management and pollution control in general; Promoting environmental education, training, and communication; Developing mapping and remote sensing tools to meet the demand for natural resources and land management; Developing environmental research on terrestrial, coastal and marine ecosystems; and Establishing mechanisms for managing and monitoring the environment, one of which was unfortunately dropped prematurely.

The reader will notice that there are only six components! As a matter of fact, one of the original components was unfortunately dropped prematurely. A major internal battle was indeed lost when the component on "preventive and mitigation measures against natural disasters" was taken off the NEAP scope. The rationale for excluding the topic was that it was (i) not truly within environmental purview and (ii) that there were no cost-effective technical solutions to this issue. In other words let's do nothing to make buildings more and better resistant to hurricanes, earthquakes and landslides. It was very disappointing. But other than that, the NEAP preparation continued over the remaining six components and, by 1989, the work was sufficiently advanced that the NEAP report could be published and widely disseminated.

\section{WHAT HAPPENED AFTER THE NEAP?}

The NEAP was translated into a policy document "La Charte de I'Environnement" which was formally adopted as a law (Law 90-033, December 21, 1990). The NEAP was essentially the proposal of a new environmental management framework and a long list of activities to be further refined and implemented for the 1990-2005 period.

Originally, the Government and the donors wanted the NEAP to be implemented in three five-year packages. Because life happens and mathematics are only for nerds, the reality has been that the packaging of the externally funded activities was in two 7/8-year projects: Environmental Project I and II (EP I and EP II).

EP I was initiated in 1991 in the face of a limited conservation baseline with the support of a broad coalition of bilateral donors (Germany, France, Switzerland, USA), international agencies $\left(\right.$ WB-IDA $^{3}$, UNDP $^{4}$, UNESCO $^{5}$ ) and NGOs (Conservation International, WWF, Wild life Conservation Society). Activities in this phase aimed at nurturing policy and regulatory reform and creating the basic institutional framework for protected area management and for ecologically compatible development ${ }^{6}$. EP II, initiated in 1997, expanded the field coverage of conservation activities, while further strengthening institutional capacities, and developing the policy framework to improve conditions for sustainability.

What have the first two externally-funded projects achieved? Measured against the key performance indicators, EP II largely met or exceeded the planned targets and brought significant accomplishments in both (i) increasing the sustainable use of natural resources in target areas; and (ii) establishing condi- tions for mainstreaming sustainable environmental and natural resources management at the national level. There were several areas, however, particularly in regard to the second objective, where EP II achievements remained short of targets.

\section{BOX 1. Madagascar at the time of the PNAE implementation} Madagascar was still under the rule of Didier Ratsiraka, an iron rule which had started in 1975. Ratsiraka's domination of the national political scene would only end in 2000 . What the first decade of this long reign had brought to the island was nothing short of isolation, poverty, a police regime and very little development prospects for a poor and increasingly desperate population.

While the 2004 population is estimated at 17.2 million, it was only about 10 million in 1989, an average growth rate of $2.6 \%$ per annum. Income per capita was low, estimated at US\$ 240, and it has barely increased in 2004 (US\$ 300), at best a little over half of the per capita income in Sub-Saharan Africa, itself the poorest continent worldwide. Life expectancy at birth was under 50 years. In 2002, it is 55 years, by contrast with economic indicators, well above Sub-Saharan Africa's average of 46. Agriculture was making up about $30 \%$ of Madagascar's Gross Domestic Product. In 2004, the GDP is US $\$ 4.4$ billion, and agriculture's share is $28.9 \%$.

\section{CAN WE CALL IT A SUCCESS?}

In respect to its first objective - increasing the sustainable use of natural resources (e.g., soil, forests, biodiversity) in the target areas - EP II achievements were satisfactory as described hereafter.

Concerning forest and land management, EP II substantially contributed to reducing the deforestation. The NASA satellite imagery and the decadal deforestation map constructed by conservation International show that deforestation rate in protected areas is four times lower than outside the parks. Importantly, an ongoing multivariate analysis of the data suggests that the relationship between the parks effect and decreased deforestation is causal, and cannot be explained just by the placement of parks in less accessible or agriculturally less attractive areas. EP II interventions also contributed to controlling the incidence of unsustainable slash-and-burn tavy agriculture in the target areas. Tavy incidence decreased by $72 \%$ during the first 4 years of the project. Following EP ॥ mix of interventions promoting conservation agriculture and soil management, soil erosion diminished from the prevailing 8 tons per hectare to 1.6 ton per hectare annually, a substantial $80 \%$ decrease while the agricultural productivity remained stable or increased. This reduction is particularly valuable given that the target areas were areas selected because of their high population, high soil vulnerability and sizeable agricultural sector.

Conservation agriculture lead to improved soil fertility as measured over a three-year period (1997-2000). Particularly significant was the increase of soil fertility on soils applying direct sowing with (zero tilling) with permanent or seasonal soil cover. In these soils, the activity and content in soil fauna increased, soil humus content improved, soil compaction diminished and soil structure improved. The thickness of top soils increased from $10-15 \mathrm{~cm}$ to $20-25 \mathrm{~cm}$. A soil analysis of basic nutrients showed that organic matter content increased by $45 \%$, nitrogen by $440 \%$, phosphorus by $600 \%$ and potassium by $218 \%$. 
Improved soil fertility contributed to improved yields for green beans, soybean, maize, and rain-fed rice which showed a yield increase of $99 \%, 170 \%, 201 \%$, and $188 \%$, respectively when compared to typical yields under traditional farming methods.

The improved use of forest resources in the target areas reduced degradation of sensitive ecosystems and decelerated the loss of biodiversity. Measured through a biodiversity index, the loss of biodiversity diminished from a level of $1.66 \%$ to a level of $0.62 \%$ during EP II. The expansion of the protected areas based on tourism that EP II catalyzed strengthened the sustainable, non-consumptive uses of biodiversity resources and demonstrated potential to generate new revenues while meeting global conservation objectives.

THE POLICY REFORM DID NOT PROGRESS AS WELL In respect to its second objective - establishing conditions for mainstreaming sustainable environmental and natural resources managementatthe nationallevel (e.g., through improvedlocal practices, national policy reform, environmental management, environ mental education) - EP II achievements were also satisfactory.

Awareness of government authorities, local communities, and civic society about environmental protection and biodiversity conservation is high. The target communities in different areas, e.g. Fianarantsoa, Sakatia, Montagne d'Ambre, have perceptibly changed their approach to environment and use of natural resources away from unsustainable practices towards seeking more livelihoods that are more sustainable and derive greater value from the natural assets, such as improved agriculture, handicraft work and ecotourism.

Policy reform to mainstream environmental considerations into economic sectors with greatest impacts on the environment has advanced substantially in mining, fisheries, aquaculture and industry sectors. Under EP II, the government approved and implemented key new policies, including policy on protected areas (POAP), policy on integrated marine and coastal zone management, national biodiversity management policy, national environmental education policy and environmental policy for road and infrastructure sector.

The policy reform, however, progressed less than planned. Several policies - tourism development policy, intellectual property protection policy, urban development policy and pesticide use policy were drafted, however not adopted or implemented by the government. The forestry policy, which was developed and adopted during EP II preparation as a condition of EP II effec tiveness, was not adequately implemented. Incomplete progress of the policy reform was a significant shortcoming of EP II.

EP II supported the strengthening of environmental management at various levels through capacity building and support to the regional environmental management offices; creation of regional environmental cells which act as an interlocutor between the government, donors and local communities; transfer of natural resource management to local communities; and transfer of management and budget decisions to the local environmental authorities and the resident staff of protected areas. Importantly for the further mainstreaming of environmental management into national development, EP II supported adoption of advanced environmental impact assessment (EIA) legislation and improvements to the EIA system. Finally, to streamline institutional arrangements, under EP II assistance, the two ministries which previously oversaw different aspects of environmental management - the Ministry of the Environment and the Ministry of Water and Forest Resources - merged into a single institution which enabled better coordination of their activities, and reinforcement of the network of their regional and local offices.

Environmental education during EP II implementation became integrated in primary and secondary schools and in the curriculum of graduate programs. Staff of agencies working in areas related to the environment received training on environmental management. Environmental considerations have been integrated into the extension services provided through NGOS and Government of Madagascar staff.

BOX 2. World Bank's Self-Ex-Post-Evaluation of what went right and wrong in the implementation of the NEAP

How does the World Bank self-evaluate the impacts of the two Environmental programs?

Major achievements of the NEAP up until to date include: (i) the enactment of enabling legislation for the protection of country's natural resources and the promotion of proper environmental management; (ii) the set-up of environmental institutions (such as the park service $A N G A P^{7}$ ) for the implementation of environmental activities and programs; (iii) the development and implementation of community-based approaches for natural resources management; (iv) the emerging evidence of positive field-level impacts in terms of reduced deforestation rates; and (v) the establishment of a platform for sustained donor support and coordination for the environment in Madagascar.

At the same time, as indicated in the Bank's Rural and Environment Sector Review (2003), there are numerous areas where the NEAP could improve its track record. The application of policies and regulations remains a challenge due to weak institutional capacity and serious governance problems, particularly in the forestry sector. Resources under the NEAP have been disproportionately invested in parallel structures at the central level, while too little has been invested to strengthen institutional capacity on the ground. Lack of rigorous priority setting has also led to a situation in which NEAP tends to drift somewhere between conservation and rural development, sometimes seeking to fill gaps that other programs such as the Plan d'Action pour le Développement Rural (Rural Development Action Plan) now seeks to fill.

Consequently, there is the notion that the operational programs of the NEAP have spread themselves too thinly, thereby contributing to the widespread feeling that more could have been achieved than actually has been. The challenge for mainstreaming of the environmental agenda is reflected in: (i) the relatively modest budget allocations for the sector; (ii) the existing limited knowledge and awareness of the Malagasy population concerning environmental issues; and (iii) the slow development of market mechanisms for the valuation of environmental services.

\section{WHERE IS MADAGASCAR IN 2006?}

Madagascar is still not doing well in 2006. Economic and social indicators are putting the country and its people among the poorest and the worst off around the globe. The island, even geographically, is not anywhere near any of the phenomenal growth centers. South Africa, the only real economic engine 
of the sub-region, is struggling with its own political and social problems. There is, however, a fresh wind of hope in Madagascar, with a dedicated and enterprising government, a strong aspiration of the young generation and, generally speaking, a big appetite for catching up with the rest of the world, a world where geographic handicaps are increasingly lessened by the cheapness of information and knowledge transfers through the Internet.

At the national level in Madagascar, the Government has just put out a great proposal to develop a 2020 vision for the country that emphasizes on inclusive development and on halting environmental degradation to sustain growth with a high stock of natural resources.

\section{WHAT IS IN THE BOOKS?}

A new project (not surprisingly called EP III) is under implementation. The objectives of EP III are to achieve the mainstreaming of environment into macroeconomic management and sector programs as well as putting into place sustainable financing mechanisms for the environment.

The project is consistent with the main goal of the CAS aimed at assisting Madagascar in accelerating poverty reduction. Following the close linkage between poverty and environmental degradation, the CAS recognizes that "Madagascar's unique biodiversity resources offer interesting revenue generating potential, which, if realized, could contribute to the reduction of poverty as well as the conservation of these resources". To unleash potential in this arena, there is a need to set access to biodiversity resources on a more rational and transparent footing as well as to develop revenue generating sources from non-extractive forest products and environmental services, of which eco-tourism, hydrological services, carbon storage and non-timber forest products are the most promising.

Where would a NEAP continuation fit in? Given the political situation of 2002 and with the unavoidable delays in processing large credits and grants to Madagascar, the preparation of EP III only started in July 2003. It is estimated that Madagascar lost about 12 million ha of forest between 1960 and 2000, effectively reducing forest cover by 50 percent in just 40 years. Following the launch of the National Environment Action Plan in the late 1980s, deforestation rates have since declined from over 400,000 ha/year in 1975-1985 to around 100,000-200,000 ha/year during the 1990s. Based on satellite imagery, it is estimated that the total area of natural forest in Madagascar declined from 9.4 million ha in 1993 to 8.5 million ha in 2000, reflecting a national average rate of deforestation of about 0.86 percent per year (World Bank, 2003 ${ }^{8}$ ).

There is clearly an urgent unfinished agenda of extending several of the NEAP success stories beyond the pilot stage into full-scale development.

The following key performance indicators have been identified for EP III: Increased proportion of terrestrial, marine and forest ecosystems under conservation and sustainable management: (i) 6 million ha of natural forests; and (ii) 100,000 ha of coastal zone and marine resources; Increased areas of ecosystems included in the national protected areas system managed by ANGAP: from 1,468,111 ha in year 1 to 2,253,848 ha in year 5 ; Improved protected areas management efficiency index (from $41 \%$ to $70 \%)$; Rate of degradation of forest and wetland resources is less than half the 1993-2000 degradation rate; Operationalization of the Malagasy Foundation for Protected Areas and Biodiversity and establishment of an endowment under the Trust Fund to be managed by the Foundation; Harmonization of sector specific legislation, environmental legal framework and international conventions through 15 strategic EIAs. Improved voice of communes in PA management through operational CROs (Comités Régionaux d'Orientation) in 27 protected areas and $80 \%$ of CROs complying with their rights and obligations as defined in Protected Areas (PA) management plans.

\section{WHAT, IF ANYTHING, DID THE NEAP BRING TO A MORE SUSTAINABLE DEVELOPMENT IN MADAGASCAR?}

Conceptually, one of the obvious limitations of the preparation of the Madagascar NEAP was, actually, the vacuum that preexisted Harlem Gro Brundlant's invention of «sustainable development» as a concept and as a potential operational approach. In the late 80 's, the world was getting ready for the Rio conference, not dreaming that it would be such a political success, and international donors like the World Bank had just started their Copernican revolution of trying to mainstream environment into international development assistance. But "poverty is the worst form of pollution" ${ }^{\prime 9}$ was still in everyone's mind in Madagascar and other poor countries. It is true that the link between environmental management and poverty reduction, at the operational level, had not been done before the end of the $20^{\text {th }}$ century and it is yet to be firmly anchored. After all, these are two extreme political and philosophical currents converging for the first time now, as I write this: the defenders of the ecology and wildlife, who set the stage for the environmental agenda, on the one hand, and the socially-conscious on the other hand, who primarily see poverty as a multi-dimensional notion in which access to environmental resources is but one of the many facets of the poverty status and tragedy. Hopefully, articles like this one can make a modest contribution towards getting these two groups around the same table.

In spite of these shortcomings, the NEAP implementation was a great real-life experiment in improved environmental management at a pilot stage. Beyond dry and sometimes unrealistic research trials, the externally-funded projects (EP I and EP II) have showed that deforestation could be slowed down, soil fertility restored and improved, erosion diminished, through a series of technical activities. It demonstrated the feasibility of such activities and helped establish the costs of doing so, a foundation upon which engineers, economists and policy makers can build for other projects and programs, in Madagascar and elsewhere. In passing, these two projects also demonstrated the feasibility, relevance and value of actual donor coordination and cooperation for better and stronger impact.

A very encouraging sign for environmentalists is the inclusion of environmental management in the recently proposed "Vision pour Madagascar et ses régions" published by the Présidence de la République. It lists environmental management as the last of the four basic objectives of the Poverty Reduction Strategy Paper (PRSP). It also puts regions and cities right and center of the improved and increased environmental management and economic growth efforts for the country between now and 2020. How to help the Malagasy Government achieve their laudable and ambitious goals? 


\section{A MODEST PROPOSAL}

A broad consultative conference (which does not have to get participants to travel to Antananarivo, but could use all the modern tools like videoconferencing) could call upon all interested in the sustainable future of Madagascar. That conference could be an honest and transparent stock-taking exercise of what has really worked in environmental management and what has not. The background would be the Madagascar 2020 vision being developed in-country, but participants would mainly focus on the multidimensional sustainable development aspects (at least, social, environmental and economic) of this vision. It could also constitute a great opportunity to integrate lessons learned from other initiatives in future interventions (e.g., regional and land-use planning) in Madagascar as well as to pave the way for more and better Public-Private Partnerships.

What might the conference achieve? If anything, more ownership by the Malagasy people of the stakes and objectives of sustainable development of one of the most touching and interesting nation on this planet.

Examples of issues which could be discussed at this conference include: How to scale up the pilot efforts of EP I and EP II and make them sustainable and significant nationally? How to reach out to the rural population and the urban poor to share the environmental management message with them? How to integrate environment in the energy sector? Ditto in regional, and more generally, decentralized development in Madagascar? How to bring more transparency and inclusion in environmental management? How to mainstream environmental education? How to go beyond so far the limited implementation of the good environmental laws?
The road out of poverty is long and windy for Madagascar, but appropriate environmental management can be implemented for everyone's benefit and help make poverty reduction efforts more sustainable.

\section{FOOTNOTES}

1 The author is deeply grateful to his beloved wife and social scientist Hedwige Jullien-Mercier for turning his initial blurp into a publishable article. Thanks should also go to Viviane Ralimanga, former colleague and now with UNDP in Antananarivo for inspiring many of the reflections presented here. The author expresses himself on a personal basis and takes full responsibility for the opinions presented in this article as well as for the possible mistakes and misinterpretations of facts.

2 A Malagasy acronym meaning "National Center for Applied Research on Rural Development", a Center created in 1974.

3 International Development Agency: it is the "soft credit» part of the World Bank Group. A credit by IDA will typically be interest free and have a repayment period of 50 years with a 10 -year grace period.

4 United Nations Development Program

5 United Nations Education, Science and Culture Organization

6 improved fuel wood management utilization practices as well as communication and extension activities aimed inducing local populations to discontinue ecologically harmful slash-and burn practices; development and establishment of alternative energy sources (other than rural electrification) to reduce pressure on forest resources and lower greenhouse gas emissions.

7 Agence Nationale de Gestion des Aires Protégées, National Agency for Protected Area Management.

8 Accessible at http://www-wds.worldbank.org/external/default/ WDSContentServer/WDSP/IB/2004/04/23/000012009_20040423101043/ Rendered/PDF/273530MG.pdf

9 The slogan of many developing countries representatives at the 1972 World Conference on Environment and Development in Stockholm (Sweden). 